\title{
Women in COVID Pandemic: Beyond Morbidity and Mortality
}

\author{
Anurag Chaudhary ${ }^{1}$ \\ Department of Community Medicine, Dayanand Medical College \\ and Hospital, Ludhiana, Punjab, India
}

Ind J Car Dis Wom:2020;5:274-277

\begin{abstract}
Address for correspondence Anurag Chaudhary, MD, Department of Community Medicine, Dayanand Medical College and Hospital, Ludhiana, Punjab 141001, India (e-mail: anuragdmc@yahoo.co.in).
\end{abstract}

\begin{abstract}
Keywords

- COVID-19 Pandemic

- domestic violence

- health care provider

- women

The COVID-19 pandemic is affecting both sexes differently in terms of morbidity and mortality. Data from all over the world highlights males as most vulnerable, but the physical, mental and social suffering of women during this pandemic is getting little mention in the literature. Problems like domestic violence are on the rise, especially during the lockdown. The sexual and reproductive health needs of the women need priority from health services in spite of being burdened during this pandemic. Globally, women make 70\% of healthcare providers; therefore, they are at risk of getting exposed to infection both at healthcare facilities and home. While working from home, women are doing more unpaid work. They are involved in childcare, household work in addition to professional work. Women working in the unorganized sector are more likely to lose their jobs and enter a financial crisis. There is a need to address these problems at national and local levels.
\end{abstract}

\section{Introduction}

The COVID-19 pandemic has produced an unprecedented situation all over the world. As the pandemic is progressing, it is unfolding unforeseen consequences besides increasing the number of infected persons and the associated morbidity and mortality. It is a known fact now that this pandemic is biased toward its effect on populations with respect to age, gender and comorbidities. The vulnerable population include males, elderly and those suffering from chronic diseases like hypertension and diabetes mellitus.

Women and men are affected by COVID-19, but biology and gender norms are influencing the disease burden. ${ }^{1}$ Scientific research has shown that men are more likely to have significant morbidity and mortality because of COVID-19. This extreme vulnerability of men may partly be explained by their relatively higher contribution to pre-existing diseases (i.e., cardiovascular disease, hypertension, diabetes, and chronic lung disease), higher risk behaviors (i.e., smoking and alcohol use), and occupational exposure. Women might possess an advantage because of behavioral and social differences prevalent in society. Prior studies suggest that women are more likely than men to follow hand hygiene practices and seek preventive care. ${ }^{2}$

Are females still more vulnerable than males? Data shows that males are more likely to die because of COVID-19 infection. ${ }^{3}$ Various published data in research journals supports this too. ${ }^{4}$ However, there is scarce mention of the silent suffering of women due to different circumstances arising on account of the COVID-19 pandemic such as lockdown. Increasing occurrence of peculiar gender-related problems are getting shadowed under tremendous magnitude of morbidity and mortality as a result of the COVID-19 pandemic.

The never seen and experienced before, long lockdowns during the pandemic have been exposing certain physical, mental and social problems, which are bothering females directly or indirectly. These problems can be listed as follows:

\section{Domestic Violence, Gender-Based Violence/ Intimate Partner Violence}

\section{Background}

The United Nations has described the worldwide increase in abuse as a shadow pandemic alongside COVID-19. Staying
(C)2020 Women in Cardiology and Related Sciences
License terms

(ㅇ)( $\Theta \circledast$ 
home is no longer safer for many women during lockdown as a surge in domestic and intimate partner violence has been observed. This was attributed to restriction of movement, loss of jobs, isolation and confinement in home, and overcrowding, all of which are leading to stress and anxiety. ${ }^{5}$

\section{Evidence}

Data for domestic violence complaints is at a 10-year high during the COVID-19 lockdown. ${ }^{6}$ Globally, there is an increase in number of cases by $20 \%$ because of confinement at home during lockdown. ${ }^{7}$ Data released by the National Legal Service Authority has observed an increase in cases of domestic violence due to the nationwide lockdown. ${ }^{8}$ Official figures reveal a $21 \%$ increase in number of crimes against women in the state of Punjab, with 700 cases of domestic violence alone. The number of cases has risen from 4709 to 5695 since March, with domestic violence cases going up from 3287 and 3933 during the lockdown period. ${ }^{9}$

\section{Suggestions}

The data shows that gender-based violence like domestic violence is dramatically increasing during the COVID-19 crisis. WHO recommends that government and policy-makers must include essential services to address violence against women in preparing and planning to tackle the crisis.

Health facilities should provide information about locally available services for survivors.

Health providers should be sensitized regarding the risk and adverse effects on health in cases of violence against women. They should offer first line support and treatment. Awareness of community members should also be increased in this regard.

Women who are experiencing violence may find it helpful to reach out to supportive family and friends, seek support from hotline, or avail local services for survivors. ${ }^{10}$

Women's centers, shelters, domestic violence help lines, and legal aid must continue to operate and expand where needed and preparators must be held accountable. ${ }^{11}$ The United Nations Population Fund (UNFPA) technical brief recommends updating gender-based violence referral pathways to reflect changes in available services in view of compromised services during the COVID-19 pandemic.

\section{Risk of Exposure to COVID-19 Infection}

\section{Background}

Around the world women comprise $70 \%$ of workers working in the health and social sector. ${ }^{12}$ Therefore, in the COVID-19 pandemic, they constitute majority of frontline workers for the provision of health services. Their work area ranges from the community where they work at the grassroots level as auxiliary nurse midwife (ANM) and accredited social health activist (ASHA) workers engaged in surveillance activities and contact tracing in field to hospitals and critical care units. This increases their risk of exposure to the COVID-19 infection. Women are not only providing care professionally but also at home to the healthy and sick family members due to their traditional role as caregiver. This too increases their risk to exposure to infection

\section{Evidence}

Data from Spain and Italy shows that almost $78 \%$ and $66 \%$ of health workers who got infected during the COVID-19 pandemic were females in Spain and Italy, respectively. ${ }^{13}$ Women and girls while providing care to sick family members got infected during the 2018 Nipah virus outbreak in India, Ebola outbreak in 2014-2016, and SARS epidemic in 2002-2003. This caregiver role puts an additional physical and psychological pressure on women.

\section{Suggestions}

Women healthcare providers need to be trained, resourced, and equipped to deal with the crisis, ensuring their protection from risk of getting infection.

The knowledge of preventive measures on the part of caregivers and healthcare workers can immensely help both the caregiver and community. ${ }^{14}$

Their role in monitoring of cases at home and informing early about symptoms could be utilized for surveillance in containment zones and for those put in home isolation.

\section{Availability of Essential Sexual and Reproductive Health Services}

\section{Background}

Pandemics reveal the worst form of gender inequalities for women and girls. This leads to poor availability of healthcare services to this vulnerable section of population. Access to essential sexual and reproductive health needs cannot be undermined in this overwhelming situation. However, the focus of health services is entirely toward provision of preventive and curative services in community and hospitals. Routine pregnancy, childbirth and immunization-related issues also demand attention from medical fraternity. Issues related to contraception like availability of contraceptives and abortion services are time-sensitive and need timely intervention.

\section{Evidence}

Approximately 2 crore child births are expected by the month of December 2019 and January 2021 in India. ${ }^{15}$ This can be linked to problem of contraceptive availability during lockdown. Similarly, availability of sanitary pads was also an issue during lockdown due to disruption in supply chains. There were instances of women going into labor on roads or in trains during the course of mass movement of migrant laborers during lockdown, thereby losing their lives in this ordeal. $^{16}$

\section{Suggestions}

Sexual and reproductive health and rights is a significant public health issue that requires high attention during pandemics. Policy-makers should scale up telemedicine for needed, evidence-based care for women and girls, including sexual and reproductive healthcare. ${ }^{17}$ 
Access to reproductive and sexual health needs can be increased by easy availability of contraceptives, including pills for medical abortion and telemedicine, in view of poor access to health facility Provision of family planning and other sexual and reproductive health commodities including menstrual health items are central to women's health. Continuity of care must be ensured in case of severe interruption of services. ${ }^{11}$

Accurate information should be given to women in the reproductive age group and pregnant women on infection prevention and possible risks. They should also be advised to seek timely consultation from health facilities in case of warning signs and emergency.

There is a need to continue with routine antenatal, natal and immunization services for women and children to save precious lives. Properly functioning health systems with strict infection prevention and control practices will be able to ensure safe pregnancies and childbirth.

\section{Problems of Working Women}

\section{Background}

Economic consequences in women cannot be neglected in this pandemic. Women working in the unorganized sector, mostly as domestic helps, and in other areas are worst affected because of loss of jobs in the wake of lockdowns. They also had to migrate to their native place as a result of their husbands losing jobs. Work from home also opened a plethora of problems for women in the form of increased domestic work in the absence of any help.

\section{Evidence}

School closure has led to increase in responsibility of women with respect to taking care of children and their online schooling This has led to an increase in amount of unpaid work at home; consequently, there is increased pressure on women. Professionally, women are doing more unpaid work by work from home. ${ }^{18}$ Recent data from the USA, UK and Germany suggests that involvement of women in pandemic-era childcare and home schooling is much more than men. ${ }^{19}$

\section{Suggestions}

It is desirable if policy-makers design recovery efforts with gender equality in mind. ${ }^{18}$ Provision of cash grants to poor women can help. In India, cash grants were provided to women who had particular type of bank account all over the country to help them financially. ${ }^{11}$

The overall solution to all the above-mentioned problems lies in promoting women in leadership roles.

Greater gender representation brings along with it diverse perspectives and approaches to problem solving, resulting in faster and better quality decisions, since feminist leadership is a form of transformative leadership that applies feminist analysis and practice to organizing and collective action. ${ }^{11}$ Therefore, the solution lies in increasing women participation in planning and decision-making for the COVID-19 pandemic at all levels, from national to local level like a village. Women's presence can highlight these issues during initial phases of planning, leading to important decisions toward gender equality. Women leaders could successfully reduce the COVID-19 transmission in their countries as compared with their male counterparts. ${ }^{11}$ However, according to a survey of 30 countries and based on CARE's experience and evidence base, average percentage of women in national level decision-making bodies is only $24 \%$ against percentage of women in global health and social care workforce, that is, 70\%, lowest percentage is in Brazil 3.7\% and highest in Canada 52.17\%. Only one country Canada has announced funding and policy commitments for gender-based violence prevention and response program in addition to sexual and reproductive health services. On the other hand, maximum countries have taken no action on gender-based violence. ${ }^{11}$

The solution and the challenge, is not to simply add women to existing structures, but to transform those structures to allow for women's meaningful participation. The keywords to emphasize in the COVID-19 pandemic are women participation in planning and decision-making at all levels and platforms.

To highlight these issues, research is required to quantify these problems, so that the resultant figures can catch attention of policy-makers followed by women representation in decision-making bodies pertaining to the COVID-19 pandemic. This will help in mitigating gender-sensitive consequences of the COVID-19 pandemic. On a positive note, this pandemic might become successful in informing the world that gender equality and women's rights are essential to getting through this pandemic and beyond.

\section{Conflicts of Interest}

None declared.

\section{References}

1 The Lancet. The gendered dimensions of COVID-19. Available at: https://www.thelancet.com/pdfs/journals/lancet/PIIS01406736(20)30823-0.pdf. Accessed June 27, 2020

2 Sharma G, Volgman AS, Michos ED. Sex differences in mortality from COVID-19 pandemic: are men vulnerable and women protected? JACC Case Rep 2020;2(9):1407-1410

3 WHO. Report of the WHO-China Joint Mission on Coronavirus Disease 2019 (COVID-19). Available at: https://www.who.int/ docs/default-source/coronaviruse/who-china-joint-missionon-covid-19-final-report.pdf?sfvrsn=fce87f4e_2. Accessed June 20, 2020

4 Jin J-M, Bai P, He W, et al. Gender differences in patients with COVID-19: focus on severity and mortality. Front Public Health 2020;8:15210.3389/fpubh.2020.00152

5 The Hindu. Domestic violence complaints at a 10-year high during COVID-19 lockdown. Available at: https://www.thehindu.com/data/data-domestic-violence-complaints-at-a-10year-high-during-covid-19-lockdown/article31885001.ece. Accessed on June 30, 2020

6 BBC News. Coronavirus: Domestic violence 'increases globally during lockdown'. . Available at: https://www.bbc.com/news/ av/world-53014211/coronavirus-domestic-violence-increases-globally-during-lockdown. Accessed June 30, 2020

7 The Times of India. Legal aid widened as domestic violence rises amid lockdown. Available at: https://timesofindia.indiatimes. com/india/legal-aid-widened-as-domestic-violence-risesamid-lockdown/articleshow/76240313.cms. Accessed June 26, 2020 
8 The Week. 700 domestic violence cases registered during lockdown in Punjab. Available at: https://www.theweek.in/ news/india/2020/04/23/700-domestic-violence-cases-registered-during-lockdown-in-punjab.html. Accessed June 22, 2020

9 Chandan JS, Taylor J, Bradbury-Jones C, Nirantharakumar K, Kane E, Bandyopadhyay S. COVID-19: a public health approach to manage domestic violence is needed. Lancet Public Health 2020;5(6):e309

10 WHO. COVID-19 and violence against women. What the health sector/system can do. Available at: https://apps.who. int/iris/bitstream/handle/10665/331699/WHO-SRH-20.04eng.pdf?ua=1. Accessed June 26, 2020

11 Where are the women? The Conspicuous absence of women in COVID-19 response teams and plans, and why we need them. CARE COVID-19 Women's Leadership Report June 2020. Available at: https://www.care.at/wp-content/uploads/ 2020/06/CARE_Where-are-the-women-in-Covid-19response.pdf. Accessed June 26, 2020

12 WHO. Delivered by women, led by men: a gender and equity analysis of the global health and social workforce. An Executive summary. World Health Organization. Available at: https:// www.who.int/hrh/resources/en_exec-summ_delivered-bywomen-led-by-men.pdf?ua=1. Accessed June 26, 2020

13 UN Women. UN Secretary-General's policy brief: The impact of COVID-19 on women (UN Women); United Nations Secretariat. Available at: https://www.unwomen.org/en/digital-library/publications/2020/04/policy-brief-the-impact-ofcovid-19-on-women. Accessed June 25, 2020
14 Papp S, Hersh M. A gender lens for COVID-19 by. Project syndicate 2020 Mar 27. Available at: https://www.project-syndicate. org/commentary/covid19-response-requires-a-gender-lensby-susan-papp-and-marcy-hersh-2020-03. Accessed June 26, 2020

15 UNICEF. Millions of pregnant mothers and babies born during COVID-19 pandemic threatened by strained health systems and disruptions in services - UNICEF. Available at: https:// www.unicef.org/rosa/press-releases/millions-pregnantmothers-and-babies-born-during-covid-19-pandemic-threatened. Accessed June 26, 2020

16 Times of India. Woman gives birth on roadside, and marches on for $160 \mathrm{KM}$. Available at: https://timesofindia.indiatimes. com/city/indore/madhya-pradesh-woman-gives-birth-onroadside-and-marches-on-for-160km/articleshow/75654249. cms. Accessed June 27, 2020

17 A Gender Lens, protecting sexual and reproductive Health and rights, and promoting gender equality. UNFPA. 2020 Mar. Available at: https://www.unfpa.org/resources/covid-19-gender-lens. Accessed June 26, 2020

18 Hall KS, Samari G, Garbers S, et al. Centring sexual and reproductive health and justice in the global COVID-19 response. Lancet 2020;395(10231):1175-1177

19 Torres N, He E. Women are bearing the brunt of the COVID-19 economic pain. Bloomberg Opinion. Available at: https:// www.bloomberg.com/graphics/2020-opinion-coronavirusgender-economic-impact-job-numbers/. Accessed June 27, 2020 